\title{
Genetics in Medicine and informatics for the genetic clinician
}

Medical geneticists depend on computer technology to do their jobs. We routinely use OMIM ${ }^{1}$, Medline ${ }^{2}, \mathrm{Helix}^{3}$, and other databases ${ }^{4}$ on the Internet to help us care for our patients. We depend on computerbased tools like the London Dysmorphology Database 5 to aid in clinical diagnosis, on semiautomated karyotyping in our cytogenetics laboratories, and on computer programs to calculate risks based on triple screening or linkage studies. Many of us "talk" more often by email with our colleagues than we do by telephone or in person.

Actually, we have little choice in the matter; our field moves so rapidly that we need all the help we can get to keep up. Even those of us who are not technophiles have been forced to learn how to type so that we can answer our patients' questions. Using a computer is the only practical way to find out quickly if a particular disease gene has been identified recently or if a new molecular test has become available.

Genetics in Medicine is a child of the Information Age. Visit our Website (html://www.wwilkins.com/esources/journdex/GIM), and you will see that this is true. You will find current Tables of Contents, abstracts, and full text (PDF) files of articles. These materials are being posted on the Website at the same time that the journal is sent for printing, so the Web-based version will be available to our subscribers before the printed copy arrives in their mail boxes. Our Website also includes continuing education exercises associated with some of our papers and a survey regarding your continuing education needs.

Genetics in Medicine will feature articles on innovative computer systems and knowledge bases that are useful to the clinical practice of genetics. We also welcome submissions that demonstrate effective use of bioinformatics in clinical genetics research and health care. We will publish reviews of new electronic media and books. We encourage our authors to provide their e-mail addresses to facilitate personal discussions regarding published work.
As Genetics in Medicine matures, we will enhance our computerbased content, both on our Website and in the printed version. We are planning to use the Website to publish additional color photographs, video clips, and audio segments to augment papers in the journal. In the future, we will make all articles available in Web-based (HTML) versions that are fully searchable and include hypertext links to other resources. You will be able to submit manuscripts directly over the Web, and our authors, reviewers, editors, publishers, and readers will all use an Internet-based system to communicate faster and more effectively.

Geneticists use computers to do their jobs effectively; so will Genetics in Medicine. E-mail us at gim@tc.umn.edu and let us know how to do this better.

Jan M. Friedman, $M D, P h D$ Department of Medical Genetics University of British Columbia

\section{References}

1. National Center for Biotechnology Information: Online Mendelian Inheritance of Man. http://www3.ncbi.nlm.nih.gov/Omim/searchomim.html

2. National Library of Medicine: Medline. http://www.ncbi.nlm.nih.gov/PubMed/

3. Children's Hospital and Regional Medical Center and University of Washington School of Medicine: Helix-A Directory of Medical Genetics Laboratories. http://healthlinks.washington.edu/helix/

4. van Steensel MA, Winter RM. Internet databases for clinical geneticists-an overview. Clin Genet 1998;53:323-330.

5. Winter R, Baraitser M. Oxford medical databases. Oxford: Oxford University Press, 1996. 